Corrigendum

\title{
Corrigendum to "Evaluating Linkages between Atmospheric Blocking Patterns and Heavy Rainfall Events across the North-Central Mississippi River Valley for Different ENSO Phases"
}

\author{
Jordan L. Rabinowitz ${ }^{1}{ }^{1}$ Anthony R. Lupo, ${ }^{1,2}$ and Patrick E. Guinan ${ }^{3}$ \\ ${ }^{1}$ Atmospheric Sciences Program, School of Natural Resources, University of Missouri, Columbia, MO, USA \\ ${ }^{2}$ Department of Natural Resources Management and Land Cadastre, Belgorod State University, Belgorod 308015, Russia \\ ${ }^{3}$ Missouri Climate Center, College of Agriculture, Food, and Natural Resources, University of Missouri, Columbia, \\ MO 65211, USA
}

Correspondence should be addressed to Jordan L. Rabinowitz; jlrxw6@mail.missouri.edu

Received 19 June 2018; Accepted 21 June 2018; Published 19 July 2018

Copyright (c) 2018 Jordan L. Rabinowitz et al. This is an open access article distributed under the Creative Commons Attribution License, which permits unrestricted use, distribution, and reproduction in any medium, provided the original work is properly cited.

In the article titled "Evaluating Linkages between Atmospheric Blocking Patterns and Heavy Rainfall Events across the North-Central Mississippi River Valley for Different ENSO Phases" [1], there was an error in the Acknowledgments section, which should be corrected as follows:

This work was partially funded by USDA Research Support Agreement nos. 58-3622-4-025 and 58-5070-5-018 under "Rainfall Rates in North-Central Missouri's LTAR."

\section{References}

[1] J. L. Rabinowitz, A. R. Lupo, and P. E. Guinan, "Evaluating linkages between atmospheric blocking patterns and heavy rainfall events across the north-central Mississippi River valley for different ENSO phases," Advances in Meteorology, vol. 2018, Article ID 1217830, 7 pages, 2018. 

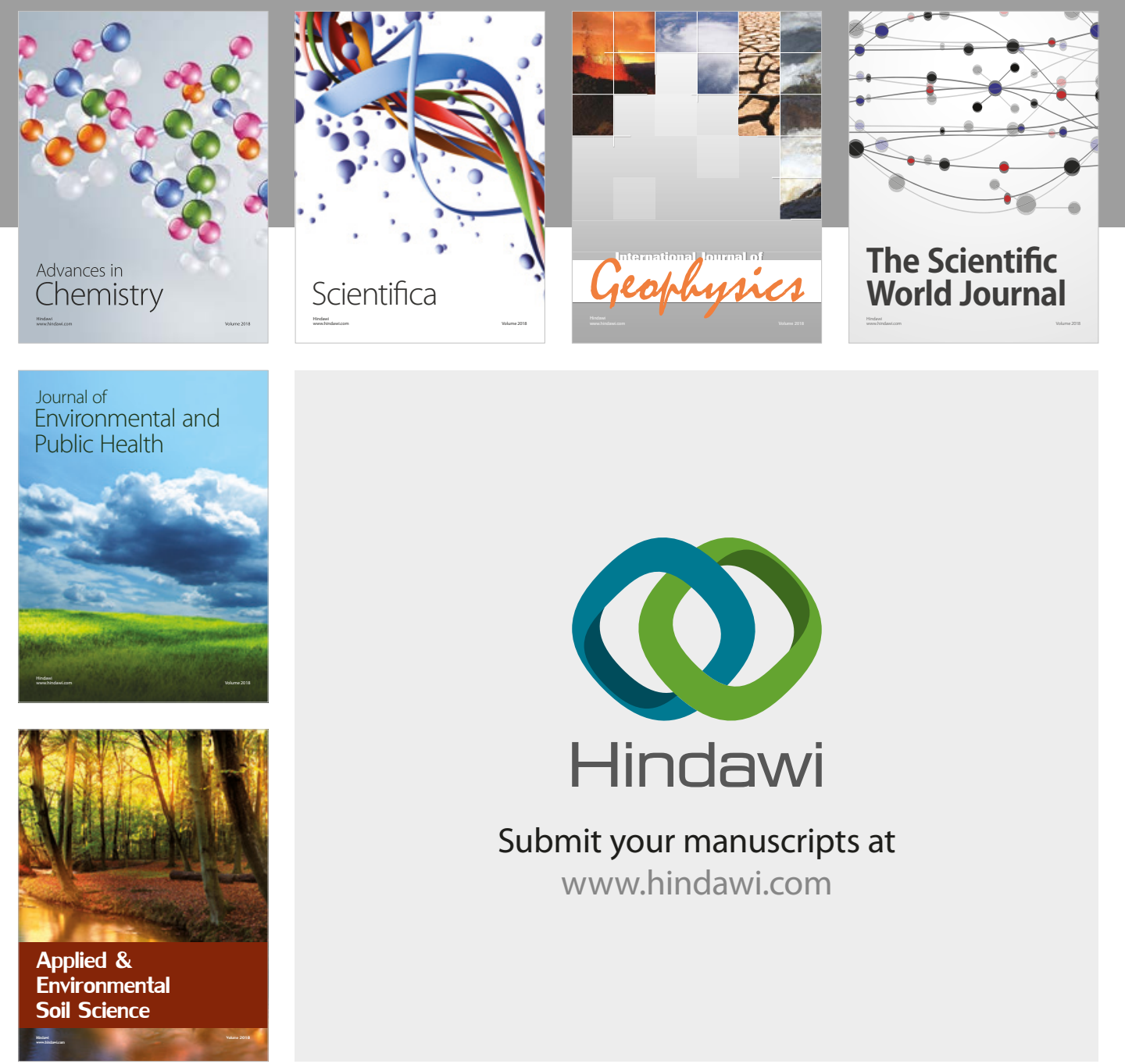

The Scientific

\section{World Journal}
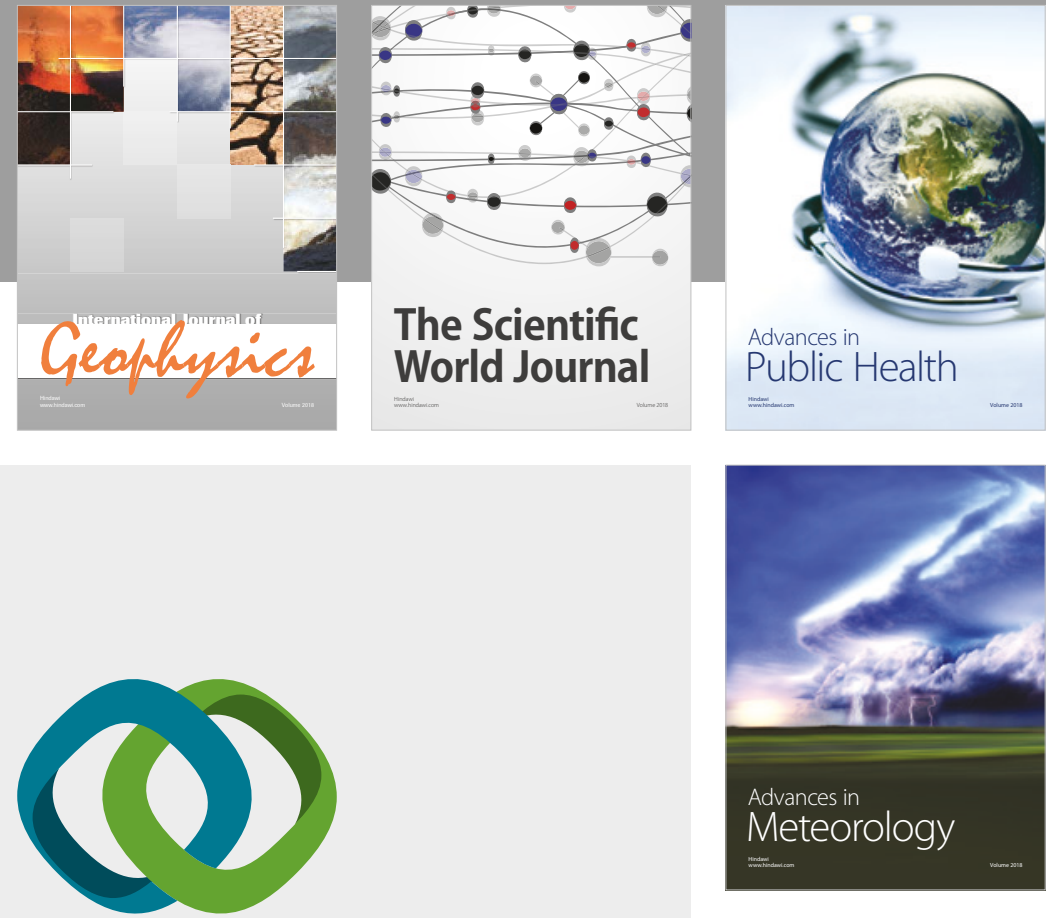

Advan

Public Health

\section{Hindawi}

Submit your manuscripts at

www.hindawi.com
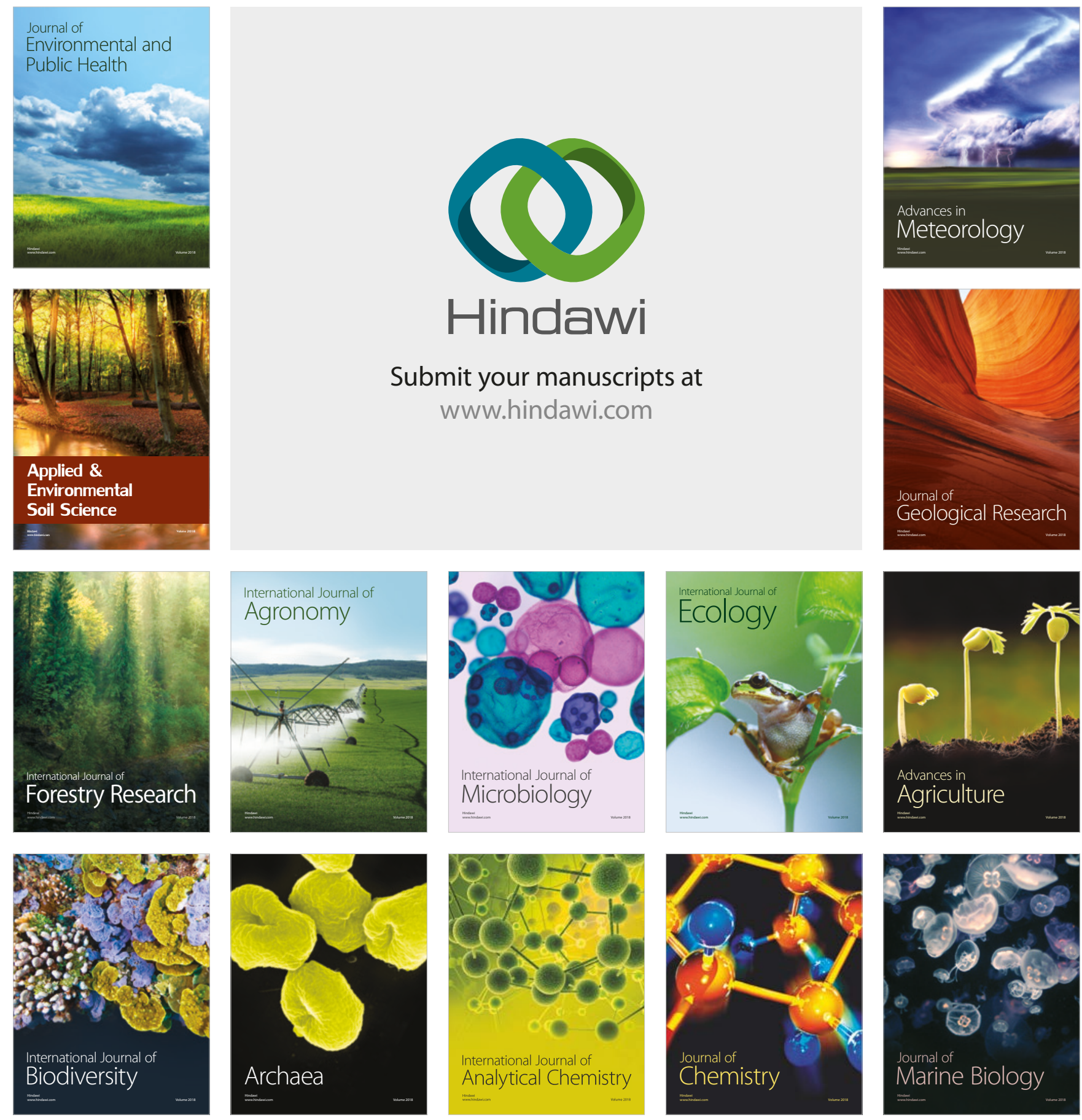